\title{
Improvement in Storage Stability of Pork Fat Using Dietary Soybean Phospholipids
}

\author{
Yoshihiro Murano $^{1 *}$, Tomoko Funabashi ${ }^{1}$, Ryosuke $\mathrm{SAKAI}^{2}$, Yumiko Hosokawa ${ }^{3}$, Yoko Mita ${ }^{2}$ and \\ Hiroyuki TAKEUCHI \\ ${ }^{1}$ Central Research Laboratory of The Nisshin OilliO Group, Ltd., 1 Shinmei-cho, Yokosuka, Kanagawa 239-0832, Japan
${ }^{2}$ Department of Dietetics, Hokuriku Gakuin Junior College, 11 Mitsukoji, Kanazawa, Ishikawa 920-1396, Japan
${ }^{3}$ Minami Kaga Health and Welfare Center, Ishikawa Prefecture, Nu 48 Sono-machi, Komatsu City, Ishikawa 923-8648, Japan
}

Received January 24, 2008; Accepted May 22, 2008

We previously reported that soybean phospholipid administration increased the oxidative stability of fish fillets. In this study, we investigated whether dietary soybean phospholipids inhibit the oxidation of n-3 PUFA-enriched pork. Pigs in the finishing period were divided into 4 groups, and fed a commercial diet, a $1.5 \%$ flax oil-supplemented diet, a $1.5 \%$ flax oil- and $1 \%$ soybean phospholipid-supplemented diet, or a $1.5 \%$ flax oil- and $1 \%$ soybean oil-supplemented diet. The n-3 PUFA content increased in the groups fed flax oil-supplemented diet. On an oxidation test of pork fat, thiobarbituric acid reactive substance (TBARS) was elevated in the group fed flax oil. In contrast, in the group fed flax oil and soybean phospholipids, TBARS elevation was inhibited to a degree similar to that in conventional pork. These results show that soybean phospholipids increased the oxidative stability of n-3 PUFA-enriched pork.

Keywords: soybean phospholipids, oxidation, lipid, pork

\section{Introduction}

N-3 polyunsaturated fatty acids (PUFAs), such as $\alpha$-linolenic acid, eicosapentaenoic acid (EPA) and docosahexaenoic acid (DHA), have been attracting attention with regard to their preventive effects on atherosclerosis (Connor, 2000), coronary arterial disease (Cullen, 2000) and hypertension (Takeuchi et al., 2007). To increase n-3 PUFA intake, livestock products (eggs, pork, etc.) with high n-3 PUFA contents have been developed (Simopoulos, 1999a; Murano et al., 2007). N-3 PUFA content is easily increased in pigs (Myer et al., 1992) because pig fat is easily affected by the dietary fatty acid composition (Wood and Enser, 1997; Sandström et al., 2000; Howe et al., 2002). Specht-Overholt et al. (1997) reported that the n-3 PUFA content of pork could be increased by up to $12 \%$ of fatty acid composition.

However, PUFAs are easily oxidized because of the presence of numerous double-bonds, and thus the oxidative stability of lipids is reduced in n-3 PUFA-enriched livestock products. For example, Young et al. (2003) reported TBARS elevation in n-3 PUFA-enriched pork. To inhibit lipid oxidation in meat, tocopherol administration has been reported to

*To whom correspondence should be addressed.

Email: y-murano@nisshin-oillio.com be effective (Rey et al., 2001), although the insufficiency of tocopherol alone has also been reported (Leskanich et al., 1997; Velasquez et al., 1998; Kouba et al., 2003). We previously reported that administration of soybean phospholipids to rainbow trout increased the oxidative stability of lipids in fish fillets (Murano et al., 2008), and we confirmed this effect in fish fillets with high n-3 PUFA contents, which indicated the possibility that feeding pigs soybean phospholipids may increase the oxidative stability of pork n-3 PUFAs. Feeding pigs n-3 PUFA-rich flaxseed oil increases the n-3 PUFA content of their fat (Romans et al., 1995a; Romans et al., 1995b). In this study, pigs in the finishing period were simultaneously fed flaxseed oil and soybean phospholipids for 67 days, and oxidation stability was evaluated by measuring thiobarbituric acid reactive substance (TBARS) content.

\section{Material and Methods}

Animals and feeding experiment For experimental diets, a commercial feed (fine NIKUTON, Showa Sangyo Co., Ltd., Tokyo, Japan) was used. The composition was as follows (g / 100 g): Protein, 14.9; lipids, 5.6; fiber, 2.3; ash, 3.5; and others, 59.6. Four experimental diets were prepared: Commercial diet (CD), $1.5 \%$ flax oil-supplemented diet (F), $1.5 \%$ flax oil- and $1 \%$ soybean phospholipid-supplemented 
diet (F-PL), and $1.5 \%$ flax oil- and 1\% soybean oil-supplemented diet (F-SO). Flax oil, phospholipid and soybean oil were purchased commercially (Nisshin OilliO Group Ltd., Tokyo, Japan.). To the 3 flax oil-added diets (F, F-PL, and F-SO), tocopherol (DL-a-tocopherol acetate, Kishida Chemical Co., Ltd., Osaka, Japan) was added at $100 \mathrm{mg} / \mathrm{kg}$. Soybean phospholipid classes are shown in Table 1. Total fatty acid composition of the experimental diets are shown in Table 2.

Twenty-eight pigs aged 16-17 weeks (LDW breed: (Large Yorkshire x Landrace) x Duroc, mean body weight: 63.0 \pm 1.0 $\mathrm{kg}$ ) born and raised at Ishikawa Livestock Research Center

Table 1. Classes of soybean phospholipids used in the experiment.

\begin{tabular}{lc}
\hline Phospholipid class & $\mathrm{g} / 100 \mathrm{~g}$ \\
\hline Phosphatidylcholine & 20.0 \\
Phosphatidylethanolamine & 14.7 \\
Phosphatidylinositol & 10.6 \\
Phosphatidic acid & 5.9 \\
Lysophosphatidylcholine & 2.2 \\
Lysophosphatidylethanolamine & 0.8 \\
\hline
\end{tabular}

Table 2. Fatty acid composition of total lipids in experimental diets.

\begin{tabular}{|c|c|c|c|c|}
\hline \multirow[b]{2}{*}{ Fatty acids } & \multicolumn{4}{|c|}{ Treatment group } \\
\hline & CD & $\mathrm{F}$ & F-PL & F-SO \\
\hline & \multicolumn{4}{|c|}{$(g / 100 g)$} \\
\hline $12: 0^{a}$ & 0.1 & 0.0 & 0.0 & 0.0 \\
\hline $14: 0$ & 0.4 & 0.3 & 0.3 & 0.3 \\
\hline $15: 0$ & 0.0 & 0.0 & 0.0 & 0.0 \\
\hline $16: 0$ & 15.2 & 12.3 & 12.9 & 12.1 \\
\hline $16: 1$ & 1.1 & 0.6 & 0.6 & 0.6 \\
\hline $17: 0$ & 0.2 & 0.2 & 0.2 & 0.2 \\
\hline $17: 1$ & 0.2 & 0.2 & 0.1 & 0.2 \\
\hline $18: 0$ & 4.2 & 3.7 & 3.8 & 3.9 \\
\hline $18: 1$ & 32.4 & 28.0 & 26.4 & 27.6 \\
\hline $18: 2(n-6)$ & 43.0 & 36.5 & 38.2 & 38.5 \\
\hline $18: 3(n-3)$ & 2.2 & 17.2 & 16.6 & 15.6 \\
\hline $20: 0$ & 0.4 & 0.3 & 0.3 & 0.3 \\
\hline $20: 1$ & 0.3 & 0.4 & 0.3 & 0.4 \\
\hline $20: 2(n-6)$ & 0.2 & 0.2 & 0.2 & 0.2 \\
\hline $20: 4(n-6)$ & 0.2 & 0.2 & 0.2 & 0.2 \\
\hline
\end{tabular}

${ }^{a}$ Number of carbon atoms: number of double bonds. were used. All groups consisted of 3 males and 4 females. Each group ( 7 animals) was maintained in a $9.4-\mathrm{m}^{2}$ pen for the feeding experiment, and were given free access to the diet and drinking water for 67 days. Body weight and food intake were measured at the initiation and end of the feeding period. After the feeding period, pigs were fasted with free access to drinking water for $24 \mathrm{~h}$, and were then sacrificed at Kanazawa Meat Processing and Storage Center (Ishikawa, Japan).

The carcasses were stored at $4^{\circ} \mathrm{C}$ for $24 \mathrm{~h}$. Loin was excised from the left half of the carcass, and the edible region at the 6-7th thoracic vertebral section was excised. The innermost layer of the dorsal fat tissues in the edible region was collected as a pork fat sample. Pork fat samples were immediately frozen at $-80^{\circ} \mathrm{C}$. Samples were used for biochemical analysis and oxidation tests.

Oxidation test Oxidation test was performed according to the method reported by Murano et al. (2008). The sample weight and size were adjusted to the specified values, and all samples were stored in a refrigerator $\left(4 \pm 0.5^{\circ} \mathrm{C}\right)$ for 3 days under strictly identical conditions. The degree of pork fat oxidation was measured before and after the oxidation period.

Biochemical analysis Total lipids in pork fat were extracted by the method reported by Folch et al. (1956). The phospholipid content, fatty acid composition, TBARS, and tocopherol content were analyzed as previously reported (Murano et al., 2008).

Statistical analysis Data are expressed as the means \pm SEM. Significant differences between the groups were determined by one-way ANOVA followed by Tukey's multiple comparison tests. Differences with a value of $P<0.05$ were considered to be significant. A statistical software package (Toukei version 2, Esumi, Tokyo, Japan) was used for all statistical analyses.

\section{Results}

The growth and feed performance of the pigs after consuming the 4 diets for 67 days are shown in Table 3. There were no significant differences in body weight or feed conversion efficiency at the end of the feeding period. SEM of the feed conversion efficiency was not calculated, as seven pigs were kept in each pen for the feeding period, and were given free access to the diet. The differences in dietary lipids did not affect the growth or feed performance.

The analytical results for pork fat after the feeding period are shown in Table 4. No significant differences were noted in lipid or phospholipid content among the groups. The groups fed flax oil were also given tocopherol, showing a significant difference in the tocopherol content from that in the CD group, but not among the F, F-PL and F-SO groups. 
Table 3. Growth of pigs and feed performance for experimental period.

\begin{tabular}{lcrcr}
\hline & \multicolumn{4}{c}{ Treatment group } \\
\cline { 2 - 5 } & \multicolumn{1}{c}{$\mathrm{CD}$} & $\mathrm{F}$ & $\mathrm{F}-\mathrm{PL}$ & F-SO \\
\hline Initial body weight $(\mathrm{kg})$ & $63.1 \pm 2.5$ & $63.4 \pm 2.4$ & $62.4 \pm 1.9$ & $63.3 \pm 1.5$ \\
Final body weight $(\mathrm{kg})$ & $108.7 \pm 3.2$ & $108.7 \pm 3.2$ & $102.6 \pm 1.6$ & $110.7 \pm 3.2$ \\
Feed conversion efficiency (\%) & 28.5 & 26.5 & 30.4 & 30.1 \\
\hline
\end{tabular}

Values are means \pm SEM, $n=7$. No significant differences were observed.

Table 4. Total lipid content, phospholipid content and total tocopherol content of fat at the end of feeding.

\begin{tabular}{|c|c|c|c|c|}
\hline & $\mathrm{CD}$ & $\mathrm{F}$ & F-PL & $\mathrm{F}-\mathrm{SO}$ \\
\hline Total lipid (g / 100g) & $92.2 \pm 0.8$ & $92.1 \pm 0.6$ & $90.4 \pm 1.0$ & $90.2 \pm 0.6$ \\
\hline Phospholipid (g/ 100g) & $0.13 \pm 0.01$ & $0.13 \pm 0.00$ & $0.13 \pm 0.00$ & $0.12 \pm 0.01$ \\
\hline Total tocopherol $(\mu \mathrm{g} / \mathrm{g})$ & $6.7 \pm 0.5 \quad a$ & $16.5 \pm 1.4 \quad b$ & $15.3 \pm 1.1 \quad b$ & $16.0 \pm 2.0 \mathrm{~b}$ \\
\hline
\end{tabular}

Values are means \pm SEM, $\mathrm{n}=7$. Letters indicate statistically significant $(p<0.05)$ differences.

Table 5. Fatty acid composition of fat at the end of feeding.

\begin{tabular}{|c|c|c|c|c|c|c|c|}
\hline & \multicolumn{7}{|c|}{ Treatment group } \\
\hline & \multicolumn{2}{|l|}{$\mathrm{CD}$} & $\mathrm{F}$ & \multicolumn{2}{|l|}{ F-PL } & \multicolumn{2}{|l|}{ F-SO } \\
\hline & \multicolumn{7}{|c|}{$(\mathrm{g} / 100 \mathrm{~g})$} \\
\hline $14: 0^{a}$ & $1.8 \pm 0.0$ & & $1.7 \pm 0.0$ & $1.5 \pm 0.1$ & & $1.7 \pm 0.1$ & \\
\hline $16: 0$ & $27.8 \pm 0.4$ & $\mathrm{a}$ & $27.2 \pm 0.3 \quad a b$ & $24.8 \pm 1.0$ & $\mathrm{~b}$ & $25.3 \pm 0.7$ & $a b$ \\
\hline $16: 1$ & $1.8 \pm 0.1$ & & $1.6 \pm 0.1$ & $7.1 \pm 3.6$ & & $4.4 \pm 2.9$ & \\
\hline $18: 0$ & $16.5 \pm 0.3$ & & $17.0 \pm 0.5$ & $13.6 \pm 2.1$ & & $15.0 \pm 0.7$ & \\
\hline $18: 1$ & $39.5 \pm 0.3$ & $\mathrm{a}$ & $37.9 \pm 0.9 \mathrm{ab}$ & $34.6 \pm 1.4$ & $\mathrm{~b}$ & $34.6 \pm 1.5$ & $\mathrm{~b}$ \\
\hline $18: 2(n-6)$ & $11.4 \pm 0.2$ & & $11.4 \pm 0.4$ & $13.5 \pm 1.4$ & & $13.9 \pm 0.5$ & \\
\hline $18: 3(n-3)$ & $0.6 \pm 0.0$ & $\mathrm{a}$ & $2.6 \pm 0.5 \mathrm{~b}$ & $4.4 \pm 0.6$ & $\mathrm{c}$ & $4.6 \pm 0.1$ & $\mathrm{c}$ \\
\hline $20: 0$ & $0.3 \pm 0.0$ & $\mathrm{a}$ & $0.2 \pm 0.1 \quad \mathrm{a}$ & $0.0 \pm 0.0$ & $\mathrm{~b}$ & $0.3 \pm 0.0$ & $\mathrm{a}$ \\
\hline $20: 4(n-6)$ & $0.1 \pm 0.0$ & & $0.1 \pm 0.0$ & $0.1 \pm 0.0$ & & $0.1 \pm 0.0$ & \\
\hline $20: 5(n-3)$ & $0.0 \pm 0.0$ & $\mathrm{a}$ & $0.1 \pm 0.0 \mathrm{~b}$ & $0.1 \pm 0.0$ & $\mathrm{~b}$ & $0.1 \pm 0.0$ & $\mathrm{~b}$ \\
\hline $24: 0$ & $0.1 \pm 0.0$ & $\mathrm{a}$ & $0.0 \pm 0.0 \mathrm{~b}$ & $0.0 \pm 0.0$ & $\mathrm{~b}$ & $0.0 \pm 0.0$ & $\mathrm{~b}$ \\
\hline $22: 6(n-3)$ & $0.1 \pm 0.0$ & & $0.1 \pm 0.0$ & $0.1 \pm 0.0$ & & $0.1 \pm 0.0$ & \\
\hline
\end{tabular}

${ }^{a}$ Number of carbon atoms: number of double bonds. Values are means \pm SEM, $n=7$. Letters indicate statistically significant $(p<0.05)$ differences.

The fatty acid composition was affected by the diet at the end of feeding, and significant differences were noted in some fatty acid contents (Table 5 ). In the F group, the $\alpha$-linolenic acid content was more than 4 times that in the $\mathrm{CD}$ group due to dietary flax oil. It was also 7 times higher in the F-PL and P-SO groups fed soybean phospholipids and soybean oil, respectively, than in the CD group. In the 3 flax oil-added diets, ratios of 16:0, 16:1, 18:1 and 18:2 were lower than with the CD diet. Contents of 16:0, 18:1 in the F-PL group and 18:1 in the F-SO group were significantly lower than $\mathrm{CD}$ group at the end of feeding period.

The oxidative stability of pork fat was evaluated by oxi- 


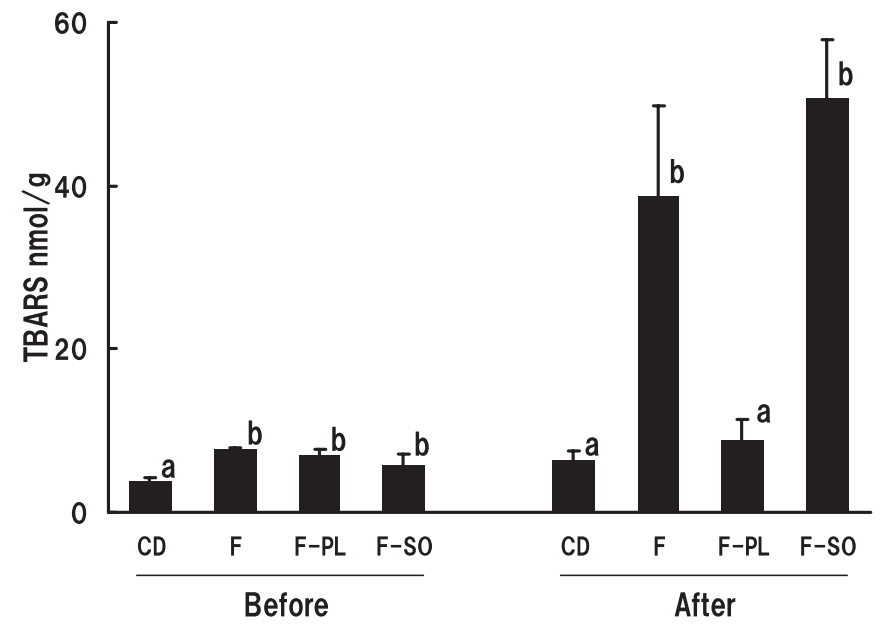

Fig. 1. Effects of dietary phospholipids on thiobarbituric acid reactive substance (TBARS) in pork fat before and after the oxidation test. Values are means \pm SEM $(n=7)$. Letters indicate statistically significant $(P<0.05)$ differences.

dation test (Fig. 1). As an index of lipid oxidation, TBARS levels were measured before and after oxidation test. TBARS levels before the test were significantly lower in the CD group fed no flax oil, but no significant difference was present among the F, F-PL and F-SO groups. TBARS levels were increased in all groups after the storage period. The elevation was marked in the F and F-SO groups, showing significant differences from those in the CD and F-PL groups. In the F-PL group fed soybean phospholipids, the elevation of the TBARS levels was inhibited after oxidation test, showing no significant differences from that in the $\mathrm{CD}$ group fed no flax oil.

\section{Discussion}

Among the 3 groups fed flax oil (F, F-PL, and F-SO groups), the elevation in TBARS levels in fat during the storage period was inhibited in the F-PL group fed soybean phospholipids, as compared to the F and F-SO groups, and the levels were similar to that in the $\mathrm{CD}$ group fed no flax. To our knowledge, this is the first report that soybean phospholipid administration inhibited the oxidation of pork fat.

An ex vivo antioxidative effect of phospholipids added to fat and oil is known. For example, phosphatidylethanolamine shows a strong antioxidative activity, and its addition to vegetable oil at $3 \%$ or higher is effective (Zambiazi and Przybylski, 1998). Chen and Nawar (1991) also reported that the primary or free amino head group of phospholipids characterizes the antioxidative activity. Phospholipids are also known to synergistically inhibit oxidation with tocopherol (Zambiazi and Przybylski, 1998). For example, Takeuchi et al. (1997) reported that the addition of phosphatidylethanol- amine and tocopherol synergistically inhibited the oxidation of triacylglycerol-type PUFA. Regarding the in vivo effects of phospholipids, improvements in abnormal lipid metabolism, lung function, arteriosclerosis, liver diseases, nerve and brain function have been reported (Fujita, 2005; Koh, 1999; Nagao and Yanagita, 2002; Schneider, 2001), but there have been few reports clarifying the effects of orally ingested phospholipids aiming at increasing in vivo oxidative stability.

Increased oxidative stability due to a rise in the content of antioxidative components of meat has been reported. For example, the increased storage stability of meat in the presence of high total tocopherol (Kim et al., 2006) or total phospholipid (Yamaguchi and Toyomizu, 1984) content has been reported. However, in this study, there were no significant differences in total tocopherol or total phospholipid content among the groups, suggesting that the mechanism was different from those reported. Oxidative stability of pork fat may be correlated with proportion of phospholipid class, in particular phosphatidylethanolamine ratio, in pork fat. The influence of soybean phospholipid administration on the phospholipid species in pork fat, particularly the ratio of phosphatidylethanolamine must be examined in the future. The soybean phospholipids used in this study contained phosphatidylcholine, phosphatidylethanolamine, phosphatidylinositol and other phospholipid species. Examining the effects of administering of individual phospholipids or different compositions of phospholipids from soybean (for instance, egg yolk phospholipids) may lead to clarification of the mechanism.

Lipid oxidative stability decreases in n-3 PUFA-enriched meat, and there is a loss in flavor due to lipid oxidation, compared to conventional meat (Takamura, 2006). To overcome these problems, tocopherol administration inhibits lipid oxidation in meat (Kim et al., 2006). However, it does not completely inhibit this oxidation. Leskanich et al. (1997) reported the difficulty of inhibiting TBARS elevation in n-3 PUFA-enriched pork. Velasquez et al. (1998) showed that the tissue tocopherol content reached a plateau when the dietary content was about $100 \mathrm{mg} / \mathrm{kg}$ in pigs during the finishing period. Our study is significant with regard to revealing the lipid oxidation-inhibitory effects of a natural plant resource other than tocopherol.

Soybean phospholipids are secondarily produced in the vegetable oil production process (Schneider, 2006; Krawczyk, 1996), but commercially distributed phospholipids account for only about $1 / 3$ of the producible amount, and not all of that produced is effectively utilized (Szuhaj, 1983). There have been several reports on the application of soybean phospholipids in feed for pigs. Øverland et al. 
(1993a; 1993b) investigated the influence of feeding soybean phospholipids during the weaning and finishing periods, but they found no improvement. Jones et al. (1992) showed that an emulsifier containing soybean phospholipids slightly increased the lipid digestibility, whereas Øverland and Sundstøl (1995) and Øverland et al. (1994) reported that this effect was not clear in a similar study. These reports failing to show the merits of dietary soybean phospholipids may be one cause of their limited utilization in the feed industry. This study clarified a new function of soybean phospholipids and clearly showed the merits of their dietary use, which may broaden their application and promote the effective utilization of plant resources.

The n-3 PUFA contents increased in the F-PL and F-SO groups. De Souza et al. (1995) showed that soybean phospholipid administration increased the PUFA digestion rate. The combination of flax oil with soybean-derived fat may efficiently increase the n-3 PUFA content of meat. The contents of 16:0 and 18:1 in the F-PL group and 18:1 in the F-SO group were significantly lower than in the $\mathrm{CD}$ group. In the F-PL and F-SO diets, ratios of 16:0 and 18:1 were lower. The differences in the fatty acid contents of pork fat might be correlated with variations in the fatty acid composition in diets. Although the contents of 16:1 and 18:2 in the CD diet were higher than in the F-PL and F-SO diets, there were no significant differences in the CD content between F-PL and F-SO. These reasons were not clarified in this study. The efficiency of fatty acid deposition in pork fat may differ with individual fatty acid species.

Although the importance of n-3 PUFA ingestion is recognized in current industrial countries (Lands, 2003; Simopoulos, 1999b), the daily fish intake in Europe is less than the n-3 PUFA requirement (Rymer and Givens et al., 2005). In Japan, fish consumption has decreased in young people aged 30 years or younger (Nishida et al., 2003). Elevation of n-3 PUFA contents in livestock products consumed in westernstyle diets are now being investigated (Jones et al., 1992; Rymer and Givens, 2005). N-3 PUFA-enriched pork facilitates a high n-3 PUFA intake without the need to markedly change eating habits (Sandström et al., 2000), but lower storage stability than conventional pork has been reported (Young et al., 2003). We demonstrated that dietary soybean phospholipids inhibit oxidation in n-3 PUFA-enriched pork fat. The improved storage stability of n-3 PUFA-enriched pork may increase its usefulness and applications.

This study showed that the dietary addition of $1 \%$ soybean phospholipids increased the lipid oxidative stability of n-3 PUFA-enriched pork to normal levels. A similar lipid oxidation-inhibitory effect was also confirmed in fish, suggesting that improved lipid oxidative stability by soybean phospholipid administration can be applied to both fish and pigs. The findings are useful for increasing the n-3 PUFAenriched pork intake and broadening the industrial value of soybean phospholipids.

\section{References}

Chen Z.Y. and Nawar W.W. (1991) Prooxidative and antioxidative effects of phospholipids on milk fat. J. Am. Oil Chem. Soc., 68 , 938-940.

Connor, W.E. (2000) Importance of n-3 fatty acids in health and disease. Am. J. Clin. Nutr., 71, 171S-175S.

Cullen, P. (2000) Evidence that triglycerides are an independent coronary heart disease risk factor. Am. J. Cardiol., 86, 943-949.

De Souza T.R., Peiniau J., Mounier A. and Aumaitre A. (1995)

Effect of addition of tallow and lecithin in the diet of weanling piglets on the apparent total tract and ileal digestibility of fat and fatty acids. Anim. Feed Sci. Technol., 52, 77-91.

Folch J., Lees M. and Stanley G.H.S. (1956) A simple method for the isolation and purification of total lipides from animal tissues. $J$. Biol. Chem., 226, 497-506.

Fujita, S. (2005) Healthy effects of soybean lecithin. New Food Industry, 47, 27-37 (in Japanese).

Howe P.R.C., Downing J.A., Grenyer B.F.S., Grigonis-Deane E.M. and Bryden W.L. (2002) Tuna fish meal as a source of DHA for n-3 PUFA enrichment of pork, chicken and eggs. Lipids, 37, 1067-1076.

Jones D.B., Hancock J.D., Harmon D.L. and Walker C.E. (1992) Effects of exogenous emulsifiers and fat sources nutrient digestibility, serum lipids, and growth performance in weanling pigs. $J$. Anim. Sci., 70, 3473-3482.

Kim, B.C., Ryu, Y.C., Cho, Y.J. and Rhee, M.S. (2006) Influence of dietary $\alpha$-tocopheryl acetate supplementation on cholesterol oxidation in retail packed chicken meat during refrigerated storage. Biosci. Biotechnol. Biochem., 70, 808-814.

Koh, Y. (1999) Bioactivity and utilization of high purity lecithin. New Food Industry, 41, 7-14 (in Japanese).

Kouba M., Enser M., Whittington F.M., Nute G.R. and Wood J.D. (2003) Effect of high-linolenic acid diet on lipogenic enzyme activities, fatty acid composition, and meat quality in the growing pig. J. Anim. Sci., 81, 1967-1979.

Krawczyk, T. (1996) Lecithin: consider the possibilities. Inform, 7, 1158-1175.

Lands W.E.M. (2003) Diets could prevent many diseases. Lipids, 38, 317-321.

Leskanich C.O., Matthews K.R., Warkup C.C., Noble R.C. and Hazzledine M. (1997) The effect of dietary oil containing (n-3) fatty acids on the fatty acid, physicochemical, and organoleptic characteristics of pig meat and fat. J. Anim. Sci., 75, 673-683.

Murano Y., Funabashi T., Seiji S. and Takeuchi H. (2008) Improvement in storage stability of fish fillet using dietary soybean phos- 
pholipids. Food Sci. Technol. Res., 14, 55-61.

Murano Y., Funabashi T., Seiji S., Aoyama T. and Takeuchi H. (2007) Effect of dietary lard containing higher $\alpha$-linolenic acid on plasma triacylglycerol in rats. J. Oleo Sci., 56, 361-367.

Myer R.O., Lamkey J.W., Walker W.R., Brendemhl J.H. and Combs G.E. (1992) Performance and carcass characteristics of swine when fed diets containing canola oil and added copper to alter the unsaturated:saturated ratio of pork fat. J. Anim. Sci., 70, 1417-1423.

Nagao, K. and Yanagita, T. (2002) Physiological functions of phospholipids. Oleoscience, 2, 129-134 (in Japanese).

Nishida Y., Nakamura M., Date K. and Nishida M. (2003) Dietary saturated and unsaturated fatty acid intakes in adults. Yamanashi Nursing Journal, 1, 7-12 (in Jananese).

Specht-Overholt S., Romans J.R., Marchello M.J., Izard R.S. Crews M.G., Simon D.M., Costello W.J. and Evenson P.D. (1997) Fatty acid composition of commercially manufactured omega-3 enriched pork products, haddock, and mackerel. J. Anim. Sci., 75, 2335-2343.

Øverland M. and Sundstøl F. (1995) Effects of lecithin on fat utilization by weanling pigs. Livest. Prod. Sci., 41, 217-224.

Øverland M., Mroz Z. and Sundstøl F. (1994) Effect of lecithin on the apparent ileal and overall digestibility crude fat and fatty acids in pigs. J. Anim. Sci., 72, 2022-2028.

Øverland M., Tokach M.D., Cornelius S.G. Pettigrew J.E. and Rust J.W. (1993a) Lecithin in swine diets: I. Weanling pigs. J. Anim. Sci., 71, 1187-1193.

Øverland M., Tokach M.D., Cornelius S.G. Pettigrew J.E. and Willson M.E. (1993b) Lecithin in swine diets: II. Growing-finishing pigs. J. Anim. Sci., 71, 1194-1197.

Rey A.I., Kerry J.P., Lynch P.B., Bote C.J., Buckley D.J. and Morrissey P.A. (2001) Effect of dietary oils and $\alpha$-tocopheryl acetate supplementation on lipid (TBARS) and cholesterol oxidation cooked pork. J. Anim. Sci., 79, 1201-1208.

Romans J.R., Johnson R.C., Wulf D.M., Libal G.W. and Costello W.J. (1995a) Effects of ground flaxseed in swine diets on pig performance and physical sensory characteristics and omega-3 fatty acid content of pork: I. Dietary level of flaxseed. J. Anim. Sci., 73, 1982-1986.

Romans J.R., Johnson R.C., Wulf D.M., Libal G.W. and Costello W.J. (1995b) Effects of ground flaxseed in swine diets on pig performance and physical sensory characteristics and omega-3 fatty acid content of pork: II. Duration of $15 \%$ dietary flaxseed. $J$. Anim. Sci., 73, 1987-1999.

Rymer C. and Givens D.I. (2005) n-3 fatty acid enrichment of edible tissue of poultry: a review. Lipids, 40, 121-130.
Sandström B., Bügel S., Lauridsen C., Nielsen F., Jensen C. and Skibsted L.H. (2000) Cholesterol-lowering potential in human subjects of fat from pigs fed rapseed oil. Br. J. Nutr., 84, 143-150.

Schneider, M. (2006) Phospholipids - what's new? Lipid Technol., 18, 250-255.

Schneider, M. (2001) Phospholipids for functional food. Eur. J. Lipid Sci. Technol., 103, 98-101.

Simopoulos, A.P. (1999b) Essential fatty acids in health and chronic disease. Am. J. Clin. Nutr., 70, 560S-569S.

Simopoulos, A.P. (1999a) New products from the agri-food industry: the return of n-3 fatty acids into the food supply. Lipids, $\mathbf{3 4}$, S297-301.

Szuhaj, B.F. (1983) Lecithin production and utilization. J. Am. Oil Chem. Soc., 60, 258A-261A.

Takamura, H. (2006) Studies on lipid deterioration and flavor change in foods. Nippon Shokuhin Kagaku Kogaku Kaishi, 53, 401-407 (in Japanese).

Takeuchi M., Hara S., Hibino H., Tanaka Y. and Totani Y. (1997) Autoxidative behavior of polyunsaturated phospholipids. III. Comparison of autoxidative behavior between polyunsaturated phospholipid and triacylglycerol. Nihon Yukagakkaishi, 46, 1489-1494 (in Japanese).

Takeuchi, H., Sakurai. C., Noda. R., Sekine. S., Murano Y., Wanaka K., Kasai M., Watanabe S., Aoyama T. and Kondo K. (2007) Antihypertensive effect and safety of dietary $\alpha$-linolenic acid in subjects with high-normal blood pressure and mild hypertension. J. Oleo Sci., 56, 347-360.

Velasquez M.P.S., Brendemuhl J.H., McDwell L.R., Sheppard K.A., Johnson D.D. and Williams S.N. (1998) Effects of supplemental vitamin $\mathrm{E}$ and canola oil on tissue tocopherol and liver fatty acid profile of finishing swine. J. Anim. Sci., 76, 110-117.

Wood J.D. and Enser M. (1997) Factors influencing fatty acids in meat and the role of antioxidants in improving meat quality. $\mathrm{Br} . \mathrm{J}$. Nutr., 78, S49-S60.

Yamaguchi, K. and Toyomizu, M. (1984) A role of phospholipid in antioxygenic action of lipids from the ordinary muscle of lean fish. Bull. Japan. Soc. Sci. Fish., 50, 1897-1903 (in Japanese).

Young J.F., Rosenvold K., Stagsted J., Steffensen C.L., Nielsen J.H. and Andersen H.J. (2003) Significance of preslaughter stress and different tissue PUFA levels on the oxidative status and stability of porcine muscle and meat. J. Agric. Food Chem., 51, 6877-6881.

Zambiazi R.C. and Przybylski R. (1998) Effect of endogenous minor components on the oxidative stability of vegetable oils. Lipid Technol., 10, 58-62. 